\title{
Review
}

\section{Leaky $\mathrm{CI}^{-}-\mathrm{HCO}_{3}{ }^{-}$exchangers: cation fluxes via modified AE1}

\author{
J. C. Ellory ${ }^{1, *}$, H. Guizouarn ${ }^{2}$, F. Borgese ${ }^{2}$, L. J. Bruce ${ }^{3}$, \\ R. J. Wilkins ${ }^{1}$ and G. W. Stewart ${ }^{4}$ \\ ${ }^{1}$ Department of Physiology, Anatomy and Genetics, University of Oxford, Oxford OX1 3PT, UK \\ ${ }^{2}$ Laboratoire de Biologie et Physiopathologie des Systèmes Intégrés, CNRS-Universite de Nice, FRE 3094, \\ Parc Valrose, Nice Cedex 2, France \\ ${ }^{3}$ Bristol Institute for Transfusion Sciences, National Blood Service, Southmead, Bristol BS10 5ND, UK \\ ${ }^{4}$ Department of Medicine, University College London, University Street, London WC1E 6f7, UK
}

The abundant membrane protein AE1 normally functions as an obligate anion exchanger, with classical carrier properties, in human red blood cells. Recently, four single point mutations of hAE1 have been identified that have lost the anion exchange function, and act as non-selective monovalent cation channels, as shown in both red cell flux and oocyte expression studies. The red cell transport function shows a paradoxical temperature dependence, and is associated with spherocytic and stomatocytic red cell defects, and haemolytic anaemias. Other forms of AE1, including the native $\mathrm{AE} 1$ in trout red cells, and the human mutation R760Q show both channel-like and anion exchange properties. The present results point to membrane domains 9 and 10 being important in the functional modification of AE1 activity.

Keywords: membrane transport; AE1; anion exchange; cation leak channels; spherocytosis; haemolytic anaemia

\section{INTRODUCTION}

The anion exchanger AE1 (synonymous with band 3; capnophorin; gene SLC4A1) is the most abundant human red cell membrane protein, present at 1.1 million copies per cell, consistent with its classical function, electroneutral $\mathrm{HCO}_{3}^{-}-\mathrm{Cl}^{-}$exchange which has to be achieved in the $300-600 \mathrm{~ms}$ period for which the red cell traverses the pulmonary circulation. As well as this transport function, the protein has a number of other important roles. It has attachment sites for the cytoskeleton via ankyrin and band 4.2 , and binding sites for haemoglobin, hemichrome and certain glycolytic enzymes (aldolase, G3PD). It has interactions with other membrane proteins, particularly glycophorin and the rhesus proteins (Tanner 1997; Bruce et al. 2003). AE1 forms oligomers in the membrane, existing in the dimeric and tetrameric forms. The final picture of this transporter is one of an ordered macromolecular complex of membrane-associated proteins (Bruce et al. 2003).

AE1 has been the topic of extensive experimental transport studies, particularly in the context of transport kinetics. It has been useful in testing simultaneous versus sequential (ping-pong) models. Studies of specificity and of the effects of $\mathrm{pH}$ have

\section{* Author for correspondence (clive.ellory@dpag.ox.ac.uk).}

One contribution of 16 to a Discussion Meeting Issue 'Membrane transport in flux: the ambiguous interface between channels and pumps'. defined alternative modes of transport, including $\mathrm{H}^{+}-$ $\mathrm{Cl}^{-}$cotransport, and $\mathrm{H}^{+}-\mathrm{SO}_{4}{ }^{2-}$ cotransport (Jennings 1976; Milanick \& Gunn 1982). The availability of high-affinity inhibitors-the stilbene disulphonates (SITS and DIDS) - has aided definition of transport activity. Although the human AE1 (hAE1) functions strictly in an obligatory anion exchange mode, with net transport, i.e. electrogenic $\mathrm{Cl}^{-}$transport occurring at a ten-thousandth of the rate of exchange transport, the trout AE1 (tAE1) mediates significant net chloride fluxes, consistent with it having anion channel-like properties. In fact, tAE1 will also allow significant transport of organic osmolytes (e.g. taurine) and even significant $\mathrm{Na}$ and $\mathrm{K}$ fluxes (Fievet et al. 1995, 1998). Physiologically this multifunctional property of tAE1 plays a role in cell volume regulation in response to swelling (Guizouarn et al. 2001).

Many different mutations of hAE 1 have been reported, which can either be asymptomatic or can lead to red cell pathologies (Bruce \& Tanner 1999). These defects can either involve structural changes in membrane-cytoskeletal interactions, leading to changes in cell shape, volume and flexibility, or can produce direct alterations (either activation or inhibition) of ion transport. Two mutations are striking in their transport effects. In southeast Asian ovalocytosis (SAO), the deletion of amino acids 400-408 from hAE1 leads to an increased cation leak, particularly when the cells are incubated at low temperatures (Bruce et al. 1999). The leak is non-specific in the sense 
that calcium ions, mannitol and sucrose also permeate SAO cells at low temperatures. The effects at $37^{\circ} \mathrm{C}$ are very small.

The second example concerns the single point mutations L687P, D705Y, S731P and H734R of hAE1. Red cells from these patients are either stomatocytic (where under the microscope a central pallor that is straight or crescent-shaped is apparent) or spherocytic (where the cells are spherical rather than discoid), and show an increased cation leak flux, often exacerbated at low temperature (Bruce et al. 2005). Expression studies in Xenopus oocytes have confirmed the modified transport function of these point mutations, and revealed a simultaneous decrease in anion exchange function (Guizouarn et al. 2007).

Several other manoeuvres can induce leak fluxes reminiscent of the fluxes seen in these hAE1 mutant cells. These include the effects of oxidation, peroxynitrite, the mercurial $p$-chloromercuriphenylsulphonic acid ( $p$ CMBS), phenazinemethosulphate and radiation (Browning et al. 2006). There are two other biological situations where a similar pathway occurs, namely malaria infection of red cells (Kirk 2001), and the channel called $\mathrm{P}_{\text {sickle }}$ seen on deoxygenation of homozygous sickle red blood cells (Gibson \& Ellory 2002). It is tempting to speculate that changes in AE1 in the membrane may be involved in the activation of these fluxes, and that this protein represents a common link in all these phenomena. The evidence for these increased cation fluxes representing a channel mode of AE1 includes (i) non-selective movement of the univalent cations $\mathrm{Li}^{+}, \mathrm{Na}^{+}, \mathrm{K}^{+}$and $\mathrm{Rb}^{+}$(Guizouarn et al. 2007), (ii) linear concentration dependence of cation flux up to $100 \mathrm{mM}$ (Bruce et al. 2005) and (iii) electrophysiological studies in Xenopus expression experiments indicating net electrogenic movement of cations (Guizouarn et al. 2007).

The present short review seeks to confirm the role of mutant AE1 in induced cation leak pathways, and to identify critical residues in $\mathrm{AE} 1$ that contribute to the new function.

\section{WHAT IS THE MAGNITUDE OF THE LEAKY CATION FLUXES?}

Figure 1 shows the increased cation leak at $0^{\circ} \mathrm{C}$ in normal and the S731P AE1 mutant red cells. The $\mathrm{K}$ $\left({ }^{86} \mathrm{Rb}\right)$ flux (expressed as a rate constant) shows a biphasic temperature response, with a minimum of approximately $20^{\circ} \mathrm{C}$, and a steep activation at low temperatures. The curve for normal red cells shows a similar, but shallower behaviour. The cation flux in the cold is increased approximately 70 -fold in the S731P mutation, leading to significant alterations in intracellular cation composition, and cell volume, with these cells being stomatocytic. Similar severe increases in leakiness were observed with the mutation H734R, with significant, but less dramatic effects occurring with L687P and D705Y. The mutation R760Q gave a more modest increased cation flux, but was particularly interesting, and is discussed in detail below. For comparison, cation fluxes in SAO red cells were also greatly enhanced, with the deletion of amino acids 400-408 leading to approximately a 100-fold increase in

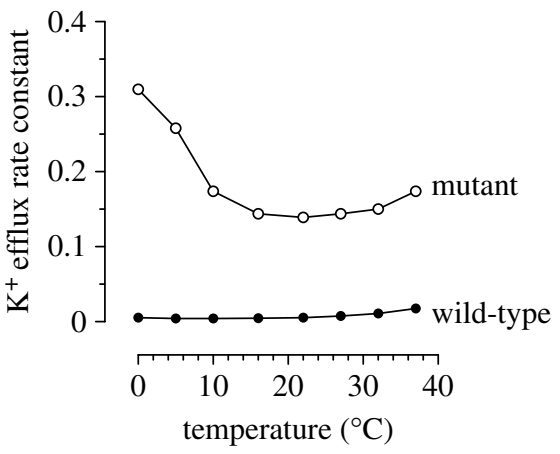

Figure 1. Temperature dependence of passive $\mathrm{K}^{+}$efflux in wild-type and AE1 S731P mutant human red blood cells. Permeability was assessed using ${ }^{86} \mathrm{Rb}^{+}$in the presence of ouabain and bumetanide.

the leak in the cold, although in experiments on these cells there are important issues in terms of cell metabolism, and different effects in fresh versus stored cells (Bruce et al. 1999). The overall conclusion from this study of AE1 mutations is that there is an induced cation flux associated with single point mutation in the amino acids in the membrane spanning helices 9-10, and also the junction between the cytoplasmic $\mathrm{N}$ terminal and helix 1 (SAO; see the cartoon in figure 2). Kinetic data showed that the enhanced $\mathrm{K}\left({ }^{86} \mathrm{Rb}\right)$ flux was linear over the concentration range $5-75 \mathrm{mM}$ (Bruce et al. 2005). The mutant AE1 cells showed a high permeability to $\mathrm{Na}, \mathrm{Li}$ and $\mathrm{K}$ consistent with the properties of a non-selective cation channel (NSCC). Comparison of cation influx and efflux data obeyed the Ussing flux-ratio equation, consistent with passive (that is, channel-like) properties. Red cell $\mathrm{Na}^{+}-\mathrm{K}^{+}$pump activity was elevated in these cells, leading to partial compensation of the low-K, high-Na intracellular composition. Inhibitor studies on the AE mutant cells indicated that the AE1 inhibitors SITS, dipyridamole and NS 1652 were all effective in reducing the cation flux consistent with acting via $\mathrm{AE} 1$, and ruled out the participation of the Gardos $\left(\mathrm{Ca}^{2+}\right.$-activated $\left.\mathrm{K}^{+}\right)$ channel in the $\mathrm{K}^{+}$flux (Bruce et al. 2005).

\section{OOCYTE EXPRESSION STUDIES}

Although the red cell data provide good evidence for the involvement of the mutant $\mathrm{AE} 1$ in the cation leak pathway, the obvious way to test this is via Xenopus oocyte expression. In a series of studies on the four single point mutations (L687P, D705Y, S731P and H734R) expressed in oocytes (Guizouarn et al. 2007), net changes in $\mathrm{Na}^{+}$and $\mathrm{K}^{+}$intracellular concentrations were seen, consistent with induced NSCCs leaking $\mathrm{Na}^{+}$inwards and $\mathrm{K}^{+}$outwards. Co-expression of glycophorin A, known to enhance AE1 expression, increased NSCC activity, and electrophysiological, ion substitution and inhibitor studies were consistent with AE1 originating the cation transport via an induced leak channel. The inability of wild-type AE1 mRNA to confer channel-like activity when expressed in Xenopus oocytes, together with the ineffectiveness of inhibitors of endogenous oocyte cation channels (which could have been activated by the expression studies) strengthened the argument that the measured fluxes were via AE1. 


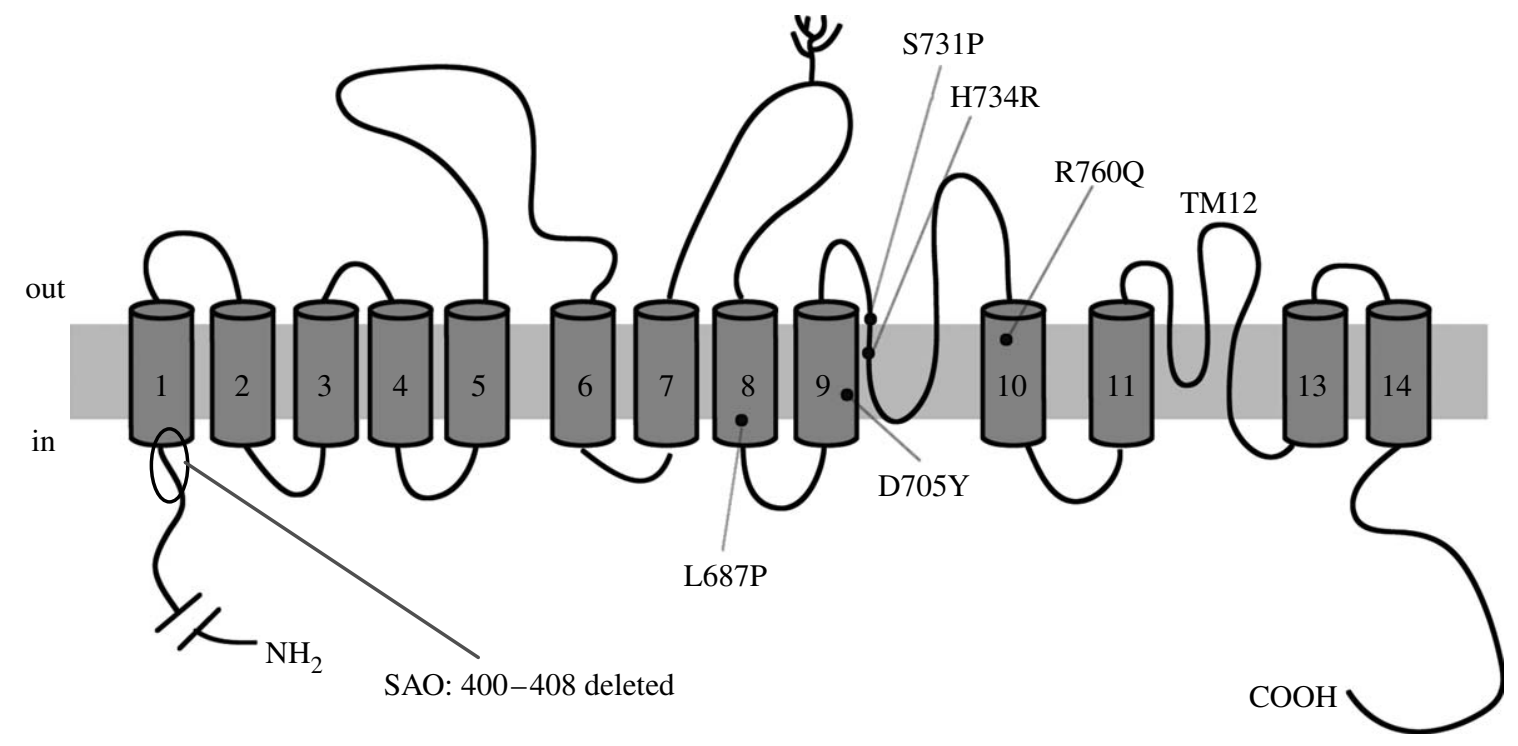

Figure 2. Cartoon illustrating the membrane topology of AE1. Sites of important single point mutations conferring cation selectivity in hAE1 are identified on membrane domains 8, 9 and 10.

\section{DOES THE MUTANT AE1 STILL TRANSPORT ANIONS?}

In many cases, loss of transport function by mutation of membrane proteins can be accounted for by misfolding or trafficking defects, which result in the protein failing to be incorporated in the plasma membrane. In the case of AE1 mutations conferring modified cation transport, a coincidence involving the benign polymorphism band 3 Memphis, in one heterozygous patient this K56E mutation was associated only with the abnormal $\mathrm{AE} 1$, thus allowing SDS-PAGE of the chymotrypsincleaved N-terminal AE1 fragment to prove membrane insertion of the H734R protein at a level of $70-80 \%$ of normal. Therefore, this is not a trafficking defect (Bruce et al. 2005). However, titration of the number of tritiated $\mathrm{H}_{2}$ DIDS binding sites on S731P red cells revealed a lower number of binding sites, indicating that the mutant AE1 did not bind this inhibitor significantly (or bound it with a greatly decreased affinity), suggesting a folding defect in the mutant protein. The obvious test for $\mathrm{AE} 1$ function is to measure anion transport activity. In two separate experimental conditions, either sulphate transport at room temperature $\left(22^{\circ} \mathrm{C}\right)$ or chloride transport at $0^{\circ} \mathrm{C}$, the mutant cells showed lower anion exchange transport rates. The sulphate efflux rate constant was halved in mutant red cells (heterozygous for mutant AE1) with any of the four single point mutations, while the rate constant of $\mathrm{Cl}$ uptake at $0^{\circ} \mathrm{C}$ was reduced from 1.66 to $0.45 \mathrm{~min}^{-1}$ in experiments on H734R red cells. Since band 3 is operationally a dimer or tetramer in the membrane, hetero-oligomers may lead to complex behaviour in inhibitor binding and transport studies.

Anion transport was also measured in the oocyte expression experiments. In this case, measurements of intracellular $\mathrm{pH}$ in response to a $\mathrm{HCO}_{3}{ }^{-} / \mathrm{CO}_{2}$ challenge (which measures $\mathrm{Cl}^{-}-\mathrm{HCO}_{3}{ }^{-}$exchange) indicated that S731P and H734R expressed in oocytes did not function as an anion exchanger, i.e. conversion to a cation channel removed the function of anion transport (Guizouarn et al. 2007).

\section{ANOTHER EXAMPLE OF MODIFIED LEAK PATHWAYS VIA AE1: THE TROUT RED CELL}

All vertebrate red cells possess AE1. In fishes, particularly trout, it has been known for a decade that trout band 3 (tAE1) has important extra transport properties, and does not function strictly in an anion exchange mode (Guizouarn et al. 2001). Experiments with oocyte expression have confirmed that tAE 1 can function predominantly as an anion channel, but simultaneously as a transport pathway for organic osmolytes, and monovalent cations, indicating a high degree of promiscuity (Fievet et al. 1995, 1998; Guizouarn et al. 2001). Physiologically, this functional modification is for cell volume regulation, in response to cell swelling: the classical regulatory volume decrease. It has been shown that the decrease in intracellular ionic strength was involved in the activation of an organic osmolyte anion channel through tAE1 (Guizouarn \& Motais 1999). The expression studies were carefully controlled to rule out the possibility of activation of endogenous cation channels in the oocyte, and other indirect effects of electrical coupling due to an increased anion conductance. Hence, although able to perform in a classical anion exchange mode, tAE 1 is in some other ways analogous to the four mutant hAE1 variants (L687P, D705Y, S731P and H734R) in that it shows channel-like properties (although, admittedly, it has greater intrinsic anion conductance-i.e. it is less cation selective). Expression of point mutations in tAE1, altering amino acid residues in membrane spanning domain 7 left exchange activity unaffected, but reduced the $\mathrm{Cl}^{-}$ conductance (Martial et al. 2006). Interestingly, mutations in the C-terminal domains lead to increased channel activity, i.e. increased conductance, with a change in selectivity. These differential effects add credence to the dual function of this transport protein.

\section{SPECIAL PROPERTIES OF BAND 3 PRAGUE II} For the four principal hAE1 mutations identified above, induction of cation channel-like properties 

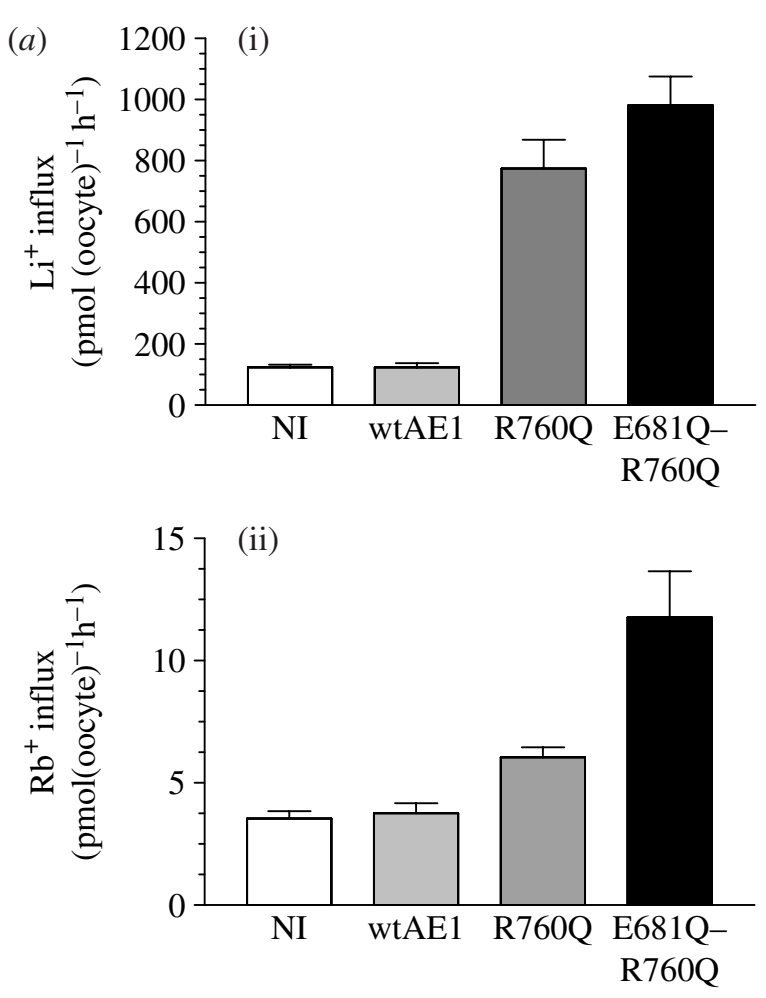

(b)
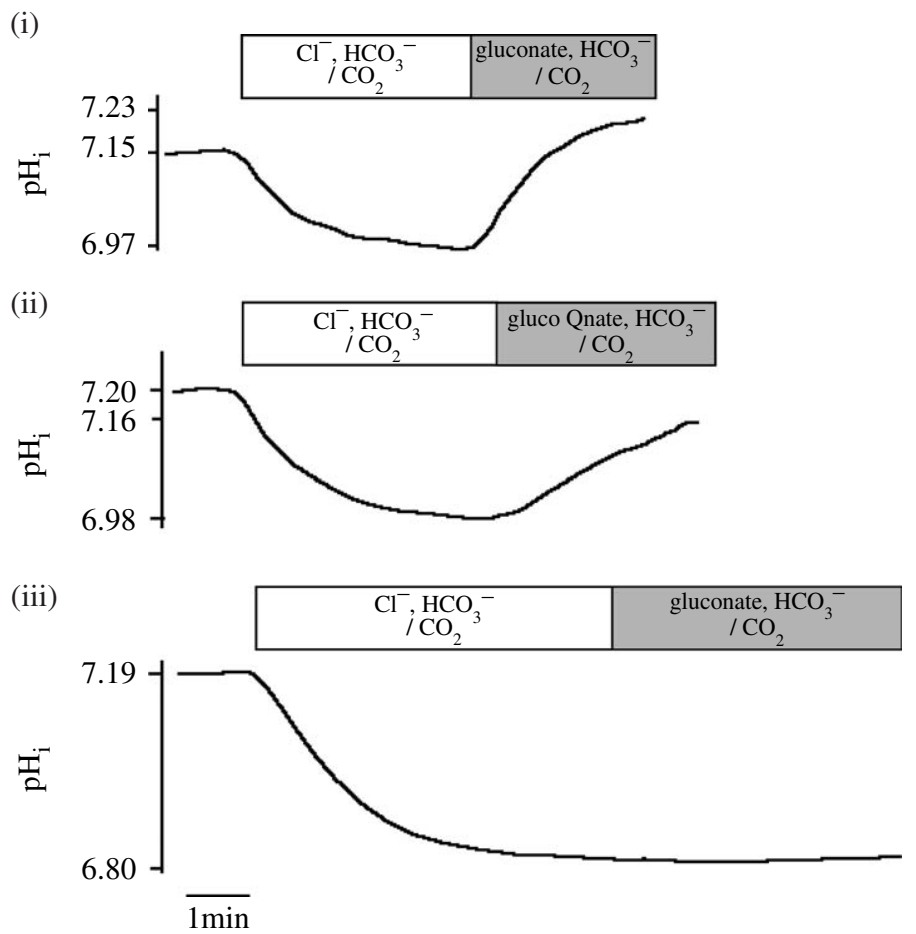

Figure 3. Xenopus oocyte expression of hAE1 wild-type (wtAE1), the AE1 R760Q mutant and the AE double mutant E681QR760Q. (a) cation influx: (i) $\mathrm{Li}^{+}$and (ii) $\mathrm{Rb}^{+}$influx, measured as previously reported (Guizouarn et al. 2001, 2007) (b) AE1 anion exchange function assessed by intracellular $\mathrm{pH}$ measurements, performed as previously reported (Guizouarn et al. 2007). (i) wt hAE1, (ii) R760Q, (iii) E681Q-R760Q. NI denotes non-injected oocytes.

abolished anion exchange. However, the mutation R760Q (identified as Prague II), which gave a significant, but more modest increase in cation permeability, particularly in the cold both in the native red cell membrane (Bruce et al. 2005) and on expression in oocytes (figure $3 a$ ), retained the ability to exchange $\mathrm{HCO}_{3}^{-}$and $\mathrm{Cl}^{-}$(figure $3 b$ ). In an attempt to dissociate the anion exchange function from the cation permeability, a double mutation was made with the added substitution E681Q-known to affect exchange properties-being combined with R760Q. In this case, exchange function is abolished, whereas cation permeability persists (figure 3). The R760Q mutation therefore exhibits some similarities to tAE 1 in its properties, and gives the dual function of channel and exchanger activity. The only other tissue expressing AE1 in which a physiological function for the transporter is recognized is the kidney, where distal tubule acidosis can result from AE1 mutations. Recently, four AE1 mutations associated with dRTA (R589H, G609R, S613F and G701D) have been expressed and assayed for function in oocytes, where they showed a significant cation leak, while retaining anion exchange function (Walsh et al. 2008). Thus, these four mutations are similar to R760Q in preserving both activities.

\section{OTHER MANOEUVRES AFFECTING CATION LEAK IN RED CELLS}

As outlined in $\S 1$, there are a number of ways in which cation leak pathways can be induced in human red cells, which are reminiscent of the AE1 mutations. Figure 4 compares the behaviour of the mutant red cells (figure $4 a$ ) with that of normal human cells in either Na-free (NMDG replacement) or thiocyanate (SCN) media (figure $4 b$ ), or with that of cells treated with the mercurial $p$ CMBS (figure $4 c$ ). An enhanced cation flux of about the same magnitude, which shows the same temperature sensitivity for all three cases, suggests that a common pathway may be activated in each condition. There are other examples in the literature, where manoeuvres as varied as sickle cell shape change or malaria invasion confer similar transport properties on the red cell (Browning et al. 2006).

\section{DISCUSSION AND CONCLUSIONS}

The membrane protein AE1 is multifunctional, and plays several varied and important structural and functional roles in the red blood cell, but its principal biological role is $\mathrm{Cl}^{-}-\mathrm{HCO}_{3}^{-}$exchange. The additional function of channel-like leak properties occurs in wild-type trout band 3, and in a number of point mutations in the hAE1. While cations can pass through the tAE 1 channel, the conductance in tAE1 is an anion conductance, being highly sensitive to $\mathrm{Cl}^{-}$ substitution by gluconate but insensitive to $\mathrm{Na}^{+}$ removal, a major difference between mutated hAE1 and tAE1. Table 1 summarizes the four possible functional situations in AE1 activity, from strictly single function to multifunctional. In any experimental situation where fluxes are induced in oocytes, there must be careful and exhaustive controls for artefacts particularly arising from activation of endogenous channels, or from the alteration of electrochemical driving forces and inducing fluxes. In the present 

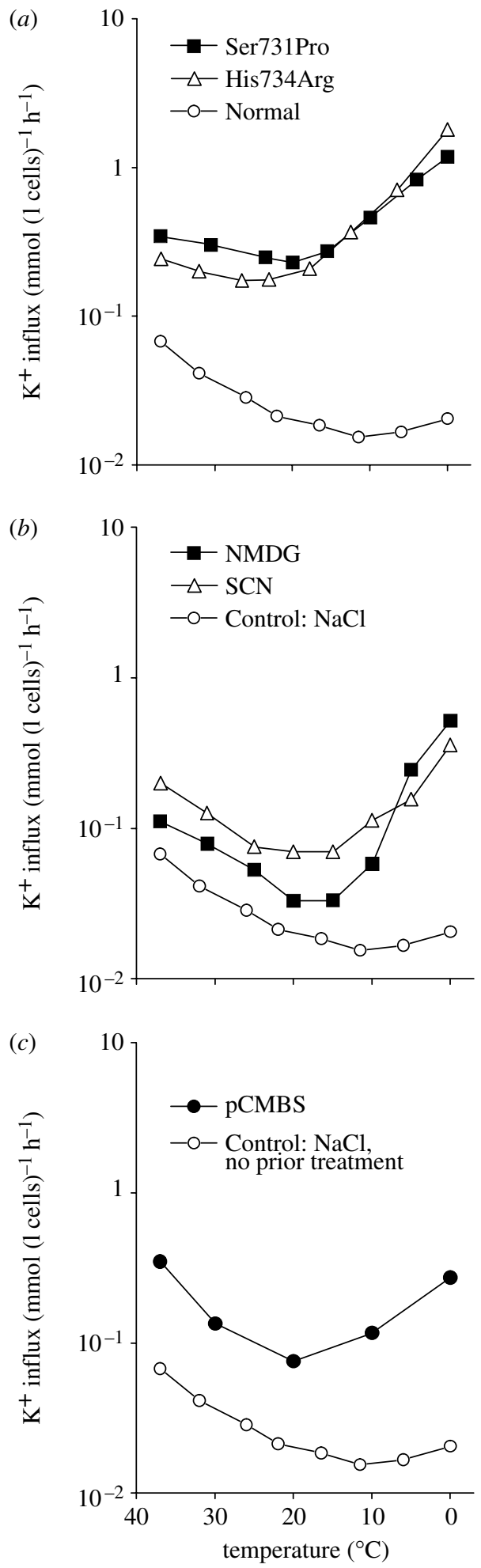

Figure 4. Temperature dependence of the ouabain- and bumetanide-resistant $\mathrm{K}^{+}$influx in normal and congenitally abnormal human red cells (Coles et al. 1999). (a) Two different AE1 mutants, Ser731Pro and His734Arg compared with normal cells. (b) Normal cells washed and suspended in either NMDGCl or NaSCN media. (c) Normal red cells in $\mathrm{NaCl}$ medium that had been treated with the sulphydryl reactive mercurial agent para-chloromercuriphenylsulphonic acid, $p$ CMBS (Cavieres 1982).

context, there is a significant body of evidence to support a direct effect of the protein as a channel rather than indirect effects.
Table 1. Four principal modes of transport performed by hAE1, its mutants and tAE1.

\begin{tabular}{ll}
\hline function & protein responsible \\
\hline $\mathrm{Cl}^{-}-\mathrm{HCO}_{3}{ }^{-}$exchange only & wt hAE1 \\
cation channel only & S731P, $\mathrm{H} 734 \mathrm{R}, \mathrm{D} 705 \mathrm{Y}$, \\
& L687P, SAO \\
$\mathrm{Cl}^{-}-\mathrm{HCO}_{3}{ }^{-}$exchange + anion & tAE1 \\
$\begin{array}{l}\text { channel } \\
\mathrm{Cl}^{-}-\mathrm{HCO}_{3}{ }^{-} \text {exchange }+ \text { cation } \\
\text { channel }\end{array}$ & R760Q, dRTA mutants \\
\hline
\end{tabular}

Although AE1 is an abundant and well-characterized protein, we lack structural detail which would allow us to define a role for the mutated amino acids in setting the mechanism and selectivity of transport. There have been truncation studies with AE1 fragments (Parker et al. 2007), and functional expression studies of chimeras between conductive and non-conductive AE1 (Borgese et al. 2004) as well as cysteine mutation studies (Martial et al. 2007), which have yielded some structural information. However, at the present time, we can only point to residues on domains $7,8,9$ and 10 as being critical to gating properties of an inner pore so that channel-like properties emerge when point mutations are carried out. The structural changes in SAO point to an involvement of amino acids (400-408) at the base of membrane-spanning domain 1 in defining transport function. By contrast, the amino acids involved in the trout channel are located in the loop between TM11 and TM13 (figure 2; Martial et al. 2006). Although it does contain consensus sequences for phosphorylation, band 3 has not been characterized as being regulated by phosphorylation (Perrotta et al. 2005). Its multiple binding sites for haemoglobin, glycolytic enzymes and hemichrome again suggest important possibilities for structural effects. However, the effects of oxygenation or deoxygenation on the mutant AE1 red cell fluxes have been shown to be negligible. The paradoxical temperature dependence of the cation fluxes is again a surprising feature, which is difficult to explain. Previously it was suggested that the flux might represent the net sum of two processes with positive or negative temperature coefficients (Stewart et al. 1980).

In the present context of the relationship between channels and carriers, the question arises of what is the likely transfer number for ions when the transporter is acting as a channel. From the red cell cation fluxes, the transport is of the order of a million ions per cell per second. With a copy number of a million for band 3, this would equate to one ion per second through the channel, a derisory value compared with the anion exchange rate of 10000 anions per second. However, this assumes that all the copies become functional channels, and are always open. If only a fraction of the protein is in channel mode, and the probability that the channel is open is low, it may be that more channel-like transfer numbers could be obtained. Until we have good structural data, and some noise analysis or single channel electrophysiology on the expressed AE1, we are unable to come to any molecular detail or mechanism to explain the dual transport mode in an 
abundant membrane protein. Nevertheless the recognition of dual properties as a carrier and a channel of modified band 3 seem to be secure.

\section{REFERENCES}

Borgese, F., Renard, C., Gabillat, N., Pellissier, B. \& Guizouarn, H. 2004 Molecular mapping of the conductance activity linked to tAE1 expressed in Xenopus oocyte. Biochim. Biophys. Acta 1664, 80-87. (doi:10.1016/ j.bbamem.2004.04.007)

Browning, J. A., Ellory, J. C. \& Gibson, J. S. 2006 Pathophysiology of red cell volume. Contrib. Nephrol. 152, 241-268. (doi:10.1159/000096327)

Bruce, L. J. \& Tanner, M. J. 1999 Erythroid band 3 variants and disease. Ballieres Best Pract. Res. Clin. Haematol. 12, 637-654. (doi:10.1053/beha.1999.0046)

Bruce, L. J., Ring, S. M., Ridgwell, K., Reardon, D. M., Seymour, C. A., Van Dort, H. M., Low, P. S. \& Tanner, M. J. 1999 South-east Asian ovalocytic (SAO) erythrocytes have a cold sensitive cation leak: implications for in vitro studies on stored SAO red cells. Biochim. Biophys. Acta 1416, 258-270. (doi:10.1016/S0005-2736 (98)00231-4)

Bruce, L. J., Beckmann, R., Ribeiro, M. L., Peters, L. L., Chasis, J. A., Delaunay, J., Mohandas, N., Anstee, D. J. \& Tanner, M. J. 2003 A band 3-based macrocomplex of integral and peripheral proteins in the RBC membrane. Blood 101, 4180-4188. (doi:10.1182/blood-2002-092824)

Bruce, L. J. et al. 2005 Monovalent cation leaks in human red cells caused by single amino-acid substitutions in the transport domain of the band 3 chloride-bicarbonate exchanger, AE1. Nat. Genet. 37, 1258-1263. (doi:10. 1038/ng1656)

Cavieres, J. D. 1982 Alteration of red cell $\mathrm{Na}$ and $\mathrm{K}$ using $p$ CMBS and nystatin. In Red cell membranes: a methodological approach (eds J. C. Ellory \& J. D. Young), pp. 179-185, 1st edn. London, UK: Academic Press

Coles, S. E., Ho, M. M., Chetty, M. C., Nicolaou, A. \& Stewart, G. W. 1999 Hereditary stomatocytosis with marked pseudohyperkalaemia. Br. f. Haematol. 104, 275-283. (doi:10.1046/j.1365-2141.1999.01191.x)

Fievet, B., Gabillat, N., Borgese, F. \& Motais, R. 1995 Expression of band 3 anion exchanger induces chloride current and taurine transport: structure-function analysis. EMBO F. 14, 5158-5169.

Fievet, B., Perset, F., Gabillat, N., Guizouarn, H., Borgese, F., Ripoche, P. \& Motais, R. 1998 Transport of uncharged organic solutes in Xenopus oocytes expressing red cell anion exchangers (AE1s). Proc. Natl Acad. Sci. USA 95, 10 996-11 001. (doi:10.1073/pnas.95.18.10996)

Gibson, J. S. \& Ellory, J. C. 2002 Membrane transport in sickle cell disease. Blood Cells Mol. Dis. 28, 303-314. (doi:10.1006/bcmd.2002.0515)
Guizouarn, H. \& Motais, R. 1999 Swelling activation of transport pathways in erythrocytes: effects of $\mathrm{Cl}^{-}$, ionic strength, and volume changes. Am. F. Physiol. 276, C210-C220.

Guizouarn, H., Gabillat, N., Motais, R. \& Borgese, F. 2001 Multiple transport functions of a red blood cell anion exchanger, tAE1: its role in cell volume regulation. f. Physiol. 535, 497-506. (doi:10.1111/j.1469-7793. 2001.t01-1-00497.x)

Guizouarn, H., Martial, S., Gabillat, N. \& Borgese, F. 2007 Point mutations involved in red cell stomatocytosis convert the electroneutral anion exchanger 1 to a nonselective cation conductance. Blood 110, 2158-2165. (doi:10.1182/blood-2006-12-063420)

Jennings, M. L. 1976 Proton fluxes associated with erythrocyte membrane anion exchange. F. Membr. Biol. 26, 187-205.

Kirk, K. 2001 Membrane transport in the malaria-infected erythrocyte. Physiol. Rev. 81, 495-537.

Martial, S., Guizouarn, H., Gabillat, N., Pellissier, B. \& Borgese, F. 2006 Consequences of point mutations in trout anion exchanger 1 (tAE1) transmembrane domains: evidence that tAE1 can behave as a chloride channel. 7. Cell. Physiol. 207, 829-835. (doi:10.1002/jcp.20631)

Martial, S., Guizouarn, H., Gabillat, N., Pellissier, B. \& Borgese, F. 2007 Importance of several cysteine residues for the chloride conductance of trout anion exchanger 1 (tAE1). F. Cell. Physiol. 213, 70-78. (doi:10.1002/jcp. 21093)

Milanick, M. A. \& Gunn, R. B. 1982 Proton-sulfate co-transport: mechanism of $\mathrm{H}^{+}$and sulfate addition to the chloride transporter of human red blood cells. F. Gen. Physiol. 79, 87-113. (doi:10.1085/jgp.79.1.87)

Parker, M. D., Young, M. T., Daly, C. M., Meech, R. W., Boron, W. F. \& Tanner, M. J. 2007 A conductive pathway generated from fragments of the human red cell anion exchanger AE1. F. Physiol. 581, 33-50. (doi:10.1113/ jphysiol.2007.128389)

Perrotta, S. et al. 2005 The N-terminal 11 amino acids of human erythrocyte band 3 are critical for aldolase binding and protein phosphorylation: implications for band 3 function. Blood 106, 4359-4366. (doi:10.1182/blood2005-07-2806)

Stewart, G. W., Ellory, J. C. \& Klein, R. A. 1980 Increased human red cell cation passive permeability below 12 degrees C. Nature 286, 403-404. (doi:10.1038/286403a0)

Tanner, M. J. 1997 The structure and function of band 3 (AE1): recent developments (review). Mol. Membr. Biol. 14, 155-165. (doi:10.3109/09687689709048178)

Walsh, S. B., Borgese, F., Gabillat, N., Unwin, R. J. \& Guizouarn, H. 2008 Cation transport activity of anion exchanger 1 (AE1) mutations found in inherited distal renal tubular acidosis (dRTA): structure-function implications for AE1. Am. F. Physiol. 295, F343-F350. 